\title{
EVALUATION OF POWER QUALITY IN OFF-GRID POWER SYSTEM
}

The energy independence, reliability and safety of energy distribution system operation as well as use of renewable resources have been hot research topics in recent years. This research leads to the development of active distribution grids with specific requirements. The Power Quality problems can arise when using renewable sources in active distribution grids. Problems are caused by decreased short-circuit power of local renewable sources, stochastic supply of electric energy from renewable sources and operating the active distribution grid in off-grid regime without connection to the external distribution system. In case of these conditions, the mutual interference between sources and loads is relevant and parameters of quality of electric energy can be exceeded. The results from analysis of quality of electric energy in the particular active distribution grid (off-grid power system) are introduced in this paper.

Keywords: Wind power generation, photovoltaic systems, power quality, hybrid power system.

\section{Introduction}

This paper introduces the initial evaluation of power quality (PQ) of an off-grid power system which was built as a research platform for renewable energy sources (RES) testing. The off-grid system was sized as a model for usual residential house supply [1].

The main idea of this concept is to find links or relations between environmental (solar irradiation and wind speed) and PQ variables associated with solar and wind energy. Based on these links the prediction of PQ for the off-grid power system will be introduced to optimize PQ level within the off-grid power system.

In particular, this contribution concentrates on the relationships between environmental (solar irradiance and wind speed) and power quality (PQ) quantities.

The paper is organized in four main sections. Section 2 provides a brief introduction to issues of power quality in general and problems specific to RES power quality. It also brings an overview of relevant technical standards. Section 3 provides a review of work on PQ prediction related to off-grid power systems. Section 4 describes an overall structure of the off-grid power system and also describes its individual components. Section 5 describes weather (solar irradiance and wind speed) data which are analyzed and some of the partial results are introduced from this data. Conclusions are presented in Section 6.

\section{Background}

Power quality can be explained as the fitness of consumed electric power to user appliances and devices. Good power quality allows electric systems to function in their intended manner without significant loss of performance or life. Without the proper power quality, an appliance (or load) may result in appliance damage or complete operation stoppage. There are many ways in which electric power can be of poor quality. And there are also many more causes of such poor quality power.

With the RES installation for off-grid power system supply, their impact on the power quality should be significant. One of the most important issues is voltage fluctuation in connection with the variability of photovoltaic (PV) and wind power generation. The other significant problem is harmonic distortion since both types of generation plants are usually connected to the power system through inverters. A wiring diagram of the described offgrid power system together with individual system components can be found in section 4. A more detailed characterization and overall off-grid power system description is fully introduced in [1] and [2].

\section{A. Power Quality}

It is not necessary to reach power quality levels defined by several international standards in off-grid power systems, but

\footnotetext{
* Stanislav Misak, Lukas Prokop, Petr Bilik, Petr Krejci

Faculty of Electrical Engineering and Computer Science VSB - Technical University of Ostrava, Ostrava, Czech Republic

E-mail: stanislav.misak@vsb.cz
} 
only good power quality allows electric devices to operate in their given manner without loss of performance or possible damage.

\section{B. Standards and Rules for $P Q$}

PQ levels in a grid connected power system are usually defined and maintained by several international technical standard organizations. The well-known are as follows: IEC (Int. Electrotechnical Commission) and the IEEE (Institute of Electrical and Electronics Engineers). In off-grid applications where PQ limits are not defined by common standards we can use for PQ evaluation limits defined for grid connected power systems.

\section{1) European Standards}

IEC61000-4-30 (2008) "Testing and measurement techniques - Power quality measurement methods" is part of series IEC61000 "Electromagnetic compatibility". It defines the methods of measurement and interpretation of results for power quality parameters in $50 / 60 \mathrm{~Hz}$ AC power supply systems. The measurement methods describe, for each type of parameter, how to obtain reliable, repeatable and comparable results regardless of the compliant instrument used for measurement and its environmental conditions. The standard defines three measurement classes A, S, B. Class A is used where precise measurements are necessary, e.g. for contractual applications to resolve disputes. The processing requirements and instrument prices for class $\mathrm{S}$ are lower. Class B is obsolete. It has the weakest requirements and it is not recommended for new designs. The standard also contains links to two other standards: IEC61000-4-7 for measurement of voltage harmonics and IEC61000-4-15 for measurement of flicker.

PQ analyzers with functionality defined in IEC61000-4-30 provide periodical data which has to be statistically processed. European standard EN 50160 describes how the measured data should be processed. It describes how to determine the main voltage characteristics of electricity supplied by public networks. It defines the "electric product" for high, medium and low voltage systems in terms of the characteristics at the supply terminals.

\section{2) IEEE Standards}

IEEE Std 1159 (2009) "Recommended Practice for Monitoring Electric Power Quality" is maintained by the Working Group for Power Quality Monitoring which was formed in response to the need for standardizing the rapidly expanding power quality monitoring manufacturing industry and the field use of their products by utilities and end-users. The standard introduces consistent terminology and definitions, and discusses power quality monitoring devices, application techniques, and the interpretation of monitoring results. It includes descriptions of conducted electromagnetic phenomena occurring in single- and poly-phase AC power systems, and encompasses the monitoring of electric characteristics of these systems. The standard describes nominal conditions and deviations from these conditions that may originate within the source of supply, load equipment, or from the interactions between the source and the load.

\section{3) Enforcement of Standards}

Both the IEEE1159 and IEC61000 series of standards cover issues of power quality. They agree on compatibility, the basic concepts and terminology. However, IEEE 1599 is not enforced; it is an informative and instructive tutorial developed by volunteers and approved by consensus. Conversely, the IEC 61000 series of standards has been developed by a group of assigned national experts through careful drafting before being approved by national voting. It is enforced at the national level by many countries.

\section{Related work}

Guidelines for the measurement and assessment of power quality characteristics for photovoltaic system are described in [3]. Harmonics, flicker, unbalance and slow voltage variations were included in these guidelines [3]. Power quality analyses for grid connected photovoltaic plants and converters were introduced in various papers; also general PQ issues associated with grid connected PV systems are discussed, for example, in [3], [4], [5] and [6].

Power quality analyses for off-grid connected power system were discussed only in a few papers. In [7] there were analyzed main factors of the impact of fluctuations of wind power from the off-grid wind power systems and energy storage technology to mitigate the off-grid wind turbine power fluctuations. Smart control systems for standalone and grid connected PV systems were introduced in [8]. Also fluctuation of total harmonics distortion (THD) in islanding mode was shortly evaluated. The THD during islanding mode of operation was around 6\% [8].

However, none of these papers provides an overall PQ analysis of the whole hybrid power system with RES. In this paper we try to find relationship between environmental, electric and PQ variables [9]. The main goal is to find interconnections between environmental variables like solar irradiance or wind speed and $P Q$ variables and arrange the basis for the $P Q$ variables prediction for off-grid power systems.

\section{System configuration}

The developed off-grid power system was designed according to requirements for usual consumption of a single family home whereas the mentioned system has to satisfy features of a smart grid system.

Basic features of the developed smart grid system are as follows: 


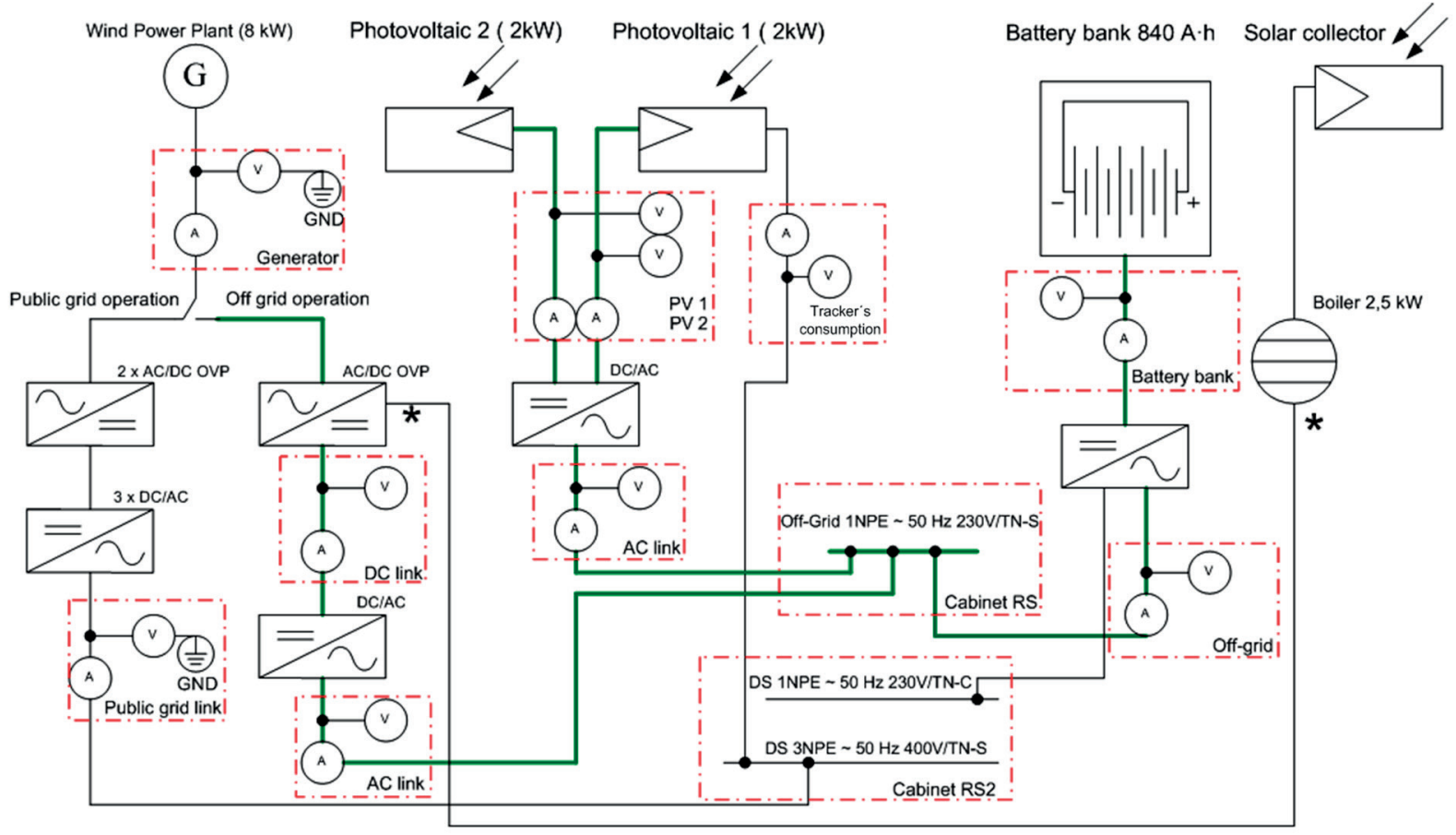

Fig. 1 The block scheme of off-grid power system

- independence on the delivering of energy from external power grids,

- operation of grid system with well-balanced production and consumption of electric energy,

- energy storage possibility,

- using mainly renewable sources of electric energy,

- nontraditional character of load,

- new conception of protection with bi-directional power flow and

- active energy management system supported by methods of artificial intelligence (main principles are illustrated in [7].)

The off-grid power system consists of three basic parts. The first part, part of sources, contains two types of renewable sources, namely a wind power plant and photovoltaic system. These types of renewable sources were selected purposefully because mutual combination of their running ensures energy supply during all year. It is given by character of individual sources where the electric energy is mainly supplied by a wind power plant for the seasons of spring and winter and by a photovoltaic system for the seasons of summer and autumn. If only one of these sources is used, it is not capable to provide enough power for the off-grid system due to the insufficient weather conditions in the Czech Republic where the system is installed. The block scheme of offgrid power system is introduced in Fig. 1.

The first source of electric energy is formed by the wind power plant (WPP) equipped with a synchronous generator with permanent magnets and the total installed capacity of $12 \mathrm{kVA}$.
The synchronous generator is connected through a protection box with controlled (AC/DC) converter and frequency converter (DC/AC) with a recuperative unit to a 1phase AC busbar with $230 \mathrm{~V}$ level and $50 \mathrm{~Hz}$ frequency. The photovoltaic system (PV1) based on monocrystalline technology is placed on the tracker for its better utilization and higher efficiency of energy conversion. PV1 has installed power similar to PV2. The photovoltaic power plant (PV2) with polycrystalline technology and the total installed output of $2 \mathrm{kWp}$ is used as another renewable electric power source. The electric output from photovoltaic system is connected also through a frequency converter (DC/AC) to the common 1phase AC busbar as a part of transmission. The PV2 with polycrystalline technology is placed on the stabile construction.

Individual appliances are supplied from the busbar and their individual connections are controlled according to the condition of the actual state of a storage device, connection priorities, character of current surge of load and the predicted value of available power from the wind and photovoltaic power plants.

Connecting of the loads according to the requirements mentioned above is done using the smart control system which also controls charging of the storage device with the total capacity of $840 \mathrm{~A} \cdot \mathrm{h}$ and voltage $48 \mathrm{~V} \mathrm{DC}$ (third part of the off-grid power system). This storage device with lead batteries balances the power and thus accumulates electric power in the case of surplus of electric power from the photovoltaic and wind power plants. This storage device works as a backup source for supply of individual power components in the case of lack of energy from power sources. The weather station is part of the off-grid 
power system conception for definition of relations between meteorological, electric and mechanical values. The weather station measures wind velocity, wind direction, temperature, relative humidity, pressure, $\mathrm{UV}$ radiation. The power flow between individual components, actual values of required parameters and total efficiency of the off-grid power system are monitored by the monitoring system in specific measuring points.

\section{Initial evaluation of the off-grid pq data}

Initial PQ evaluation was processed in compliance with European standard EN 50160 and a database of monitored variables (meteorological and electric) was used. The following marks "-“ for power production and "+" for power consumption are used in this initial evaluation.

Two weekly periods (from January 24 to January 30, 2014 and from May 1 to May 7, 2014) were chosen from long-term power quality measurements. The first week (January) represents the evaluation of the system in the on-grid mode with the operating photovoltaic power plant and wind power plant. The second week (May) represents the evaluation of the system in the off-grid mode with the operating photovoltaic power plant only. So far the results are not available for the off-grid mode with both sources operating.

Values of flicker, harmonic voltages and THDu are shown in Table 1. The short-term flicker severity (Pst) was chosen for the figure instead of long-term flicker severity (Plt) due to better information.

Values of flicker, harmonics voltages and THDu

Table 1

\begin{tabular}{|l|c|c|}
\hline & on-grid WPP+PV & off-grid PV \\
\hline Pst_1 & 0.93 & 4.81 \\
\hline PIt_1 & 1.06 & 4.77 \\
\hline Uharm[\%]3_1 & 5.37 & 6.73 \\
\hline Uharm[\%]5_1 & 2.95 & 1.90 \\
\hline Uharm[\%]7_1 & 0.59 & 0.69 \\
\hline Uharm[\%]9_1 & 0.28 & 0.31 \\
\hline Uharm[\%]11_1 & 0.31 & 0.31 \\
\hline Uharm[\%]13_1 & 0.33 & 0.23 \\
\hline Uharm[\%]15_1 & 0.16 & 0.10 \\
\hline Uharm[\%]17_1 & 0.22 & 0.06 \\
\hline Uharm[\%]19_1 & 0.15 & 0.04 \\
\hline Uharm[\%]21_1 & 0.08 & 0.04 \\
\hline Uharm[\%]23_1 & 0.23 & 0.04 \\
\hline Uharm[\%]25_1 & 0.14 & 0.03 \\
\hline THDu[\%]_1 & 6.59 & 7.05 \\
\hline
\end{tabular}


affected by the power of connected photovoltaic and wind power plants. Higher values of flicker may have originated either in the background of network or in changes of load at the point of measurement.

Figures 5 - 6 show waveforms of frequency, flicker and power of photovoltaic power plant in the off-grid mode (May). We can see that during the supply of power from the photovoltaic power plant, the frequency increased to about $52 \mathrm{~Hz}$, and also the value of the short-time flicker severity significantly increased to 6 .
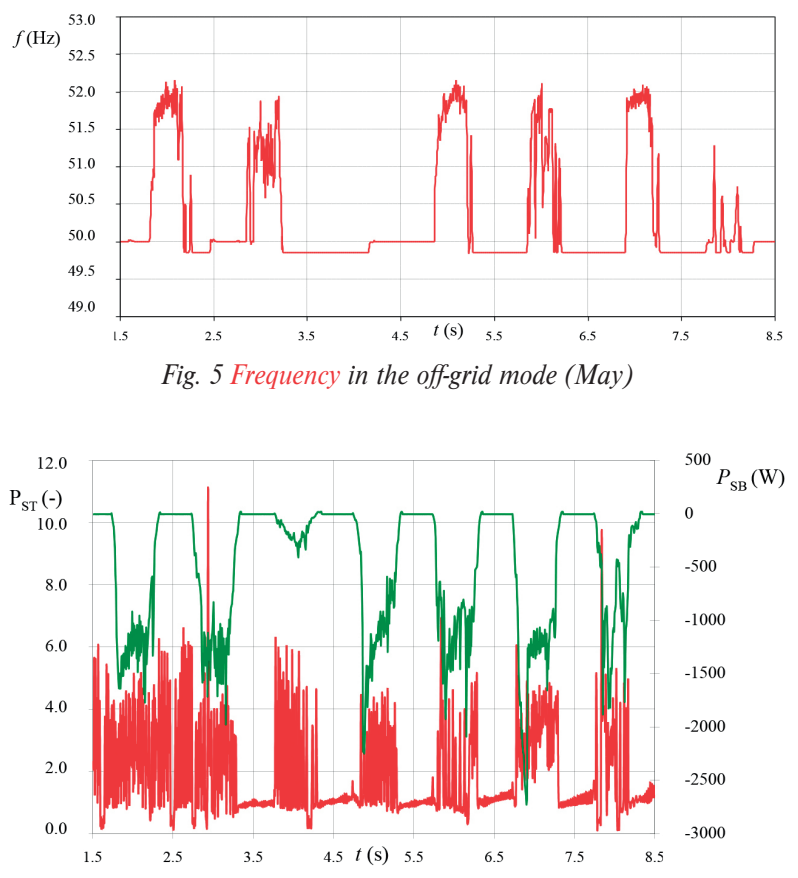

Fig. 6 Flicker and photovoltaic power in the off-grid mode (May)

\section{Conclusions and future work}

Utilization of solar and wind power in off-grid power systems for residential house supply is in contradiction with the increasing PQ sensitivity of equipment and devices being connected to the off-grid power system. Defined links and relations between the solar radiation and wind speed and direction allow reduction of the negative effects of solar and wind power and of course defined links and relations help to keep acceptable level of PQ.

This paper introduces initial evaluation of power quality in the hybrid power system where both on-grid and off-grid operation modes are possible.

\section{Acknowledgement}

This work was supported within the framework of the IT4Innovations Centre of Excellence project, reg. no. CZ.1.05/1.1.00/02.0070 supported by Operational Programme 'Research and Development for Innovations' funded by the Structural Funds of the European Union and state budget of the Czech Republic, Additionally, this article has been elaborated in the framework of the project New creative teams in priorities of scientific research, reg. no. CZ.1.07/2.3.00/30.0055, supported by the Operational Program Education for Competitiveness and co-financed by the European Social Fund and the state budget of the Czech Republic, project ENET - Energy Units for Utilization of non-Traditional Energy Sources CZ.1.05/2.1.00/03.0069, Students Grant Competition project reg. no. SP2015/178, project LE13011 Creation of a PROGRES 3 Consortium Office to Support Cross-Border Cooperation and project InterEnergy (CZ.1.07/2.3.00/20.0075).

\section{References}

[1] MISAK, S., PROKOP, L.: Technical-Economic Analysis of Hybrid Off-Grid Power System, Prof. of $11^{\text {th }}$ intern. Scientific conference Electric power engineering 2010, (Drapela, J. Machacek, J, ed.), pp. 295-300, Brno: Univ Technol, May 2010.

[2] MISAK, S., PROKOP, L.: Off-Grid Power Systems. Intern. Conference on Environment and Electrical Engineering 2010. ISBN 9781-4244-5370-2, pp. 23-26.

[3] ORTEGA, M. J., HERNANDEZ, J. C., GARCIA, O. G.: Measurement and Assessment of Power Quality Characteristics for Photovoltaic Systems: Harmonics, Flicker, Unbalance, and Slow Voltage Variations, Electric Power Systems Research, vol. 96, March 2013, pp. 23-35, ISSN 0378-7796, 10.1016/j.epsr.2012.11.003.

[4] AL-HADDAD, K.: Power Quality Issues under Constant Penetration Rate of Renewable Energy into the Electric Network, $14^{\text {th }}$ intern. Power Electronics and Motion Control Conference (EPE/PEMC), 2010, pp.S11-39, S11-49, Sept. 2010.

[5] DRABEK, P., KUS, V.: EMC Issues of Low Frequency Interference of Power Electronic Converters. Applied Mechanics and Materials, vols. 284-287, 2013, pp. 2516-2520, ISSN 1662-7482, doi: 10.4028/www.scientific.net/AMM.284-287.2516.

[6] OTCENASOVA, A., ALTUS, J., HECKO, P., ROCH, M.: Measurement Characteristics of Voltage in Practice and Possibilities for Improvement of Voltage, Przeglad elektrotechnniczny - Electrical Review, Varsava, 2012, R. 88 NR 9a/2012, pp. 103-106, ISSN 0033-2097, WOS:000308318000021 


\section{COMMNICOIIONS}

[7] MOSTAFA, H. A., SHATSHAT, R. E., SALAMA, M. M. A.: Smart Control System for Standalone and Grid Connected PV Systems, Power and Energy Society General Meeting, 2012 IEEE, pp. 1-6, July 2012.

[8] HOGER, M., BRACINIK, P., ROCH, M.: Simulation of a Power Substation's Control System Operation, Communications Scientific Letters of the University of Zilina, 13(2A), 2011, pp. 44-48.

[9] FARHOODNEA, M., MOHAMED, A., SHAREEF, H., ZAYANDEHROODI, H.: Power Quality Analysis of Grid-Connected Photovoltaic Systems in Distribution Networks, Przeglad Elektrotechniczny - Electrical Review, 2013, vol. 89, No. 2A, pp. $208-213$. 